\title{
On Analysis of Chemistry Teaching Model among Proficient Teacher and Novices in the Project of Outstanding Teacher Education
}

\author{
Chengyin Yanga ${ }^{a}$, Sixin Li, Xueqing Shen \\ School of Chemistry \& Chemical Engineering, Shaanxi Normal University, Xi'an 710119, China \\ ayangcy@snnu.edu.cn
}

\begin{abstract}
This article compared two teachers' classroom language skills, based on the model of heterogeneous teaching in the same lesson, which has been organized by two chemistry teachers from one of the standardized high school in China. In their professional development, one is proficient teacher S, the other is a novice teacher L. The teaching content is "the chemical equilibrium constant", which is selected from PEP chemistry textbooks. Using the improved Flanders Interaction Analysis System (iFIAS) quantitatively analyze their classes. The conclusion is that the proficient teacher classroom language is more practical, for novice teachers to improve classroom teaching, promote personal professional development, to provide a basis.
\end{abstract}

Keywords: outstanding teacher; classroom observation; novice teacher; proficient teacher; iFIAS.

\section{Introduction}

The western international carried out outstanding teacher education program for improving their teachers' quality at the turn of the century. It aims to cultivate outstanding teachers, and promote both the professional development of teachers and the quality of basic education. There is a sentence from the ministry of education on the opinions of the outstanding teacher training plan, which enacted by Chinese government and explicitly pointed out that cultivating a large number of primary and secondary school teachers, who owns noble ethics, professional knowledge, outstanding education teaching ability and high-quality specialization of self-development ability [1].

Classroom teaching is the best way for teachers' professional development, which combines the proficient teachers with novice teachers having outstanding further training directions. By means of the classroom observation to research their teaching languages and gathering lessons' facts and data to discover the factors that affecting the growth of the novice teachers.

\section{Concept Definition}

The heterogeneous classes are for the same subject and teaching content, taking different ideas, methods, design styles and different ways of implementation, to achieve the same result [2].

Classroom Observation comes from the western ideological trend of scientism, as a method of studying class, developed in the 1950s and 1960s. It is a professional activity observing the communication of classroom by recording, analyzing and researching, which seek the improvement of students' learning and promote the teachers' professional development [3].

Usually the title of senior, more than 15 years teaching experience are called expert teachers. Novice teachers' teaching experience is between $0 \sim 5$ years and in between the two is the proficient teachers [4].

\section{Research Object}

This study adopted the school-based research way of the heterogeneous classes, analyzing the chemistry classes of the teacher $\mathrm{S}$ and teacher $\mathrm{L}$ from a high school in $\mathrm{Xi}$ 'an. The high school is a provincial standardized school. Teacher $\mathrm{S}$ has 14 years of teaching experience. Teacher $\mathrm{L}$ is a chemical education master with limited teaching experience. According to the normal teaching schedule, this research content is the Chemical Equilibrium Constant from the People's Education Press (PEP). 


\section{Research Tool}

As a research tool, Flanders (N. A. Flanders) Interactive Analysis System was born in the 1960s [5].

In 2012 [6], Chinese scholar Haiguang Fang et al. proposed improved Flanders Interaction Analysis System (iFIAS) as shown in table 1.

Table 1 Improved Flanders Interaction Analysis System (iFIAS)

\begin{tabular}{|c|c|c|c|}
\hline & ssification & Category & Category \\
\hline \multirow{7}{*}{ Teacher Talk } & \multirow{4}{*}{ Indirect Influence } & 1 & Accepts Feeling \\
\hline & & 2 & Praises or Encourages \\
\hline & & 3 & Accepts or Uses Ideas of Student \\
\hline & & 4 & $\begin{array}{l}\text { 4.1 Asks Opening Problems } \\
\text { 4.2 Asks Closed Problems }\end{array}$ \\
\hline & \multirow{3}{*}{ Direct Influence } & 5 & Lecturing \\
\hline & & 6 & Giving Directions \\
\hline & & 7 & Criticizing or Justifying Authority \\
\hline \multirow{4}{*}{\multicolumn{2}{|c|}{ Student Talk }} & 8 & Student Response Passively \\
\hline & & 9 & 9.1 Student Response Initiatively \\
\hline & & 9 & 9.2 Student Question Initiatively \\
\hline & & 10 & Discuss with partner \\
\hline \multirow{2}{*}{\multicolumn{2}{|c|}{ Silence }} & 11 & Confusion Unhelpful for Teaching \\
\hline & & 12 & Silence Helpful for Teaching \\
\hline \multirow{2}{*}{\multicolumn{2}{|c|}{ Technology }} & 13 & Teacher Apply Technology \\
\hline & & 14 & Student Apply Technology \\
\hline
\end{tabular}

\section{The Matrices of Interaction Analysis}

This study encoded the lesson of teacher $\mathrm{S}$ and teacher $\mathrm{L}$ and obtained 863 and 887 codes respectively, then formed 862 and 886 "order pairs". Calculated the frequency of "order pair" and filled it in the matrix. The results of teacher $\mathrm{S}$ are shown in Table 2.

Table 2 Teacher S' Interactive Analysis Matrix

\begin{tabular}{|c|c|c|c|c|c|c|c|c|c|c|c|c|c|c|c|c|c|c|}
\hline \multirow{2}{*}{\multicolumn{2}{|c|}{$\mathrm{S}$}} & \multirow{2}{*}{1} & \multirow{2}{*}{2} & \multirow{2}{*}{3} & \multicolumn{2}{|c|}{4} & \multirow{2}{*}{5} & \multirow{2}{*}{6} & \multirow{2}{*}{7} & \multirow{2}{*}{8} & \multicolumn{2}{|c|}{9} & \multirow{2}{*}{10} & \multirow{2}{*}{11} & \multirow[b]{2}{*}{12} & \multirow{2}{*}{13} & \multirow{2}{*}{14} & \multirow{2}{*}{ Total } \\
\hline & & & & & 4.1 & 4.2 & & & & & 9.1 & 9.2 & & & & & & \\
\hline & 1 & 0 & 0 & 0 & \multicolumn{2}{|c|}{0} & 0 & 0 & 0 & 0 & \multicolumn{2}{|c|}{0} & 0 & 0 & 0 & 0 & 0 & 0 \\
\hline & 2 & 0 & 0 & 0 & \multicolumn{2}{|c|}{0} & 0 & 0 & 0 & 0 & \multicolumn{2}{|c|}{0} & 0 & 0 & 0 & 0 & 0 & 0 \\
\hline \multicolumn{2}{|r|}{3} & 0 & 0 & 27 & 0 & 7 & 6 & 0 & 0 & 0 & 1 & 0 & 0 & 0 & 1 & 5 & 0 & 47 \\
\hline \multirow{6}{*}{4} & 4.1 & \multirow{2}{*}{0} & \multirow[b]{2}{*}{0} & 0 & 0 & 0 & 0 & & 0 & 1 & \multirow{2}{*}{\multicolumn{2}{|c|}{0}} & \multirow{2}{*}{0} & \multirow{2}{*}{0} & 0 & 0 & 0 & 1 \\
\hline & 4.2 & & & 1 & & 50 & 17 & 0 & 1 & 36 & & & & & 3 & 2 & 0 & 110 \\
\hline & 5 & 0 & 0 & 0 & 1 & 35 & 273 & 0 & 0 & 1 & 0 & 1 & 2 & 0 & 6 & 41 & 0 & 360 \\
\hline & 6 & 0 & 0 & 0 & \multicolumn{2}{|c|}{0} & 0 & 3 & 0 & 0 & \multicolumn{2}{|c|}{0} & 0 & 0 & 1 & 0 & 0 & 4 \\
\hline & 7 & 0 & 0 & 0 & \multicolumn{2}{|c|}{0} & 1 & 0 & 0 & 0 & & & 0 & 1 & 0 & 0 & 0 & 2 \\
\hline & 8 & 0 & 0 & 17 & 0 & 6 & 14 & 0 & 0 & 31 & 1 & 0 & 0 & 0 & 0 & 9 & 0 & 78 \\
\hline 9 & 9.1 & 0 & 0 & 1 & & & 1 & & 0 & 0 & 1 & 0 & 0 & 0 & 0 & 0 & 0 & 3 \\
\hline 9 & 9.2 & 0 & 0 & 0 & & & 0 & 0 & 0 & 0 & 0 & 0 & 1 & 0 & 0 & 0 & 0 & 1 \\
\hline & 10 & 0 & 0 & 0 & & & 3 & 0 & 0 & 0 & & & 0 & 0 & 0 & 0 & 0 & 3 \\
\hline & 11 & 0 & 0 & 0 & & & 0 & 0 & 1 & 0 & & & 0 & 0 & 0 & 0 & 0 & 1 \\
\hline & 12 & 0 & 0 & 0 & 0 & 2 & 9 & 0 & 0 & 1 & & & 0 & 0 & 81 & 1 & 0 & 94 \\
\hline & 13 & 0 & 0 & 1 & 0 & 10 & 36 & 1 & 0 & 9 & & & 0 & 0 & 2 & 99 & 0 & 158 \\
\hline & 14 & 0 & 0 & 0 & & & 0 & 0 & 0 & 0 & & & 0 & 0 & 0 & 0 & 0 & 0 \\
\hline & Total & 0 & 0 & 47 & 1 & 110 & 360 & 4 & 2 & 79 & 3 & 1 & 3 & 1 & 94 & 157 & 0 & 862 \\
\hline
\end{tabular}

\subsection{Analysis That Refer to Teacher Behavior}

In the matrix, the intersection of the 1-3 rows and the 1-3 columns is a positive integration area. The intersection of the 7-8 rows and the 6-7 columns is a negative integration area. Having calculated the frequency, the author got the table 3 . 
Table 3 Teacher Behavior

\begin{tabular}{ccc}
\hline & $\mathrm{S}$ & $\mathrm{L}$ \\
\hline Positive integration area & 27 & 23 \\
The ratio of positive integration & $3.13 \%$ & $2.60 \%$ \\
Negative integration area & 0 & 0 \\
The ratio of negative integration & $0 \%$ & $0 \%$ \\
\hline
\end{tabular}

Table 4 Teacher Talk Structure

\begin{tabular}{ccccc}
\hline & & S & & L \\
& Frequency & Proportion & Frequency & Proportion \\
\hline Teacher Talk & 524 & $60.79 \%$ & 422 & $47.63 \%$ \\
Student Talk & 86 & $9.98 \%$ & 53 & $5.98 \%$ \\
Silence & 95 & $11.02 \%$ & 154 & $17.38 \%$ \\
Technology & 157 & $18.21 \%$ & 257 & $29.01 \%$ \\
\hline
\end{tabular}

Both $\mathrm{S}$ and $\mathrm{L}$ negative integration frequency are 0 . It shows that teachers and students respect each other and teaching activities are carried out in harmonious atmosphere. While the L's positive integrate proportion is less than the $\mathrm{S}$. Therefore, $\mathrm{S}$ teacher's class is more relaxed and can arouse the enthusiasm of students.

\subsection{Analysis That Refer to Teacher-Student Language Structure}

Based on iFIAS, analyzing the interactive analysis matrix, the results are shown in Table 4 and figure 1.

Both S and L, the proportion of Teacher Talk is much larger than the Student Talk. S Teacher Talk have accounted for $85.90 \%$. Additionally, L Teacher Talk has achieved $88.84 \%$. It can be seen that their teaching is a teacher led teaching, which are contrary to the educational idea that "The teacher must play a leading role while the students should play an important role". The proportion of Teacher Talk to teacher-student talk, from this point, the L is higher than the S. L always lectured or assigned the students to answer the question. In contrast, students always respond to $\mathrm{S}$ questions initiatively. Therefore the classroom atmosphere of $\mathrm{S}$ is free.

From the ratio of Silence and Technology, two teachers reached $10 \%$ or more than $20 \%$. Specific dates are shown in Table 5 and Table 6.

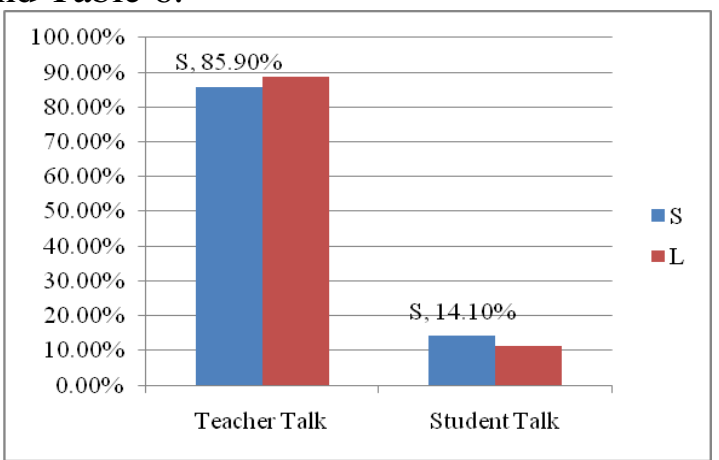

Fig. 1 The ratio of Teacher Talk and Student Talk

Table 5 Analysis of Silence and Technology

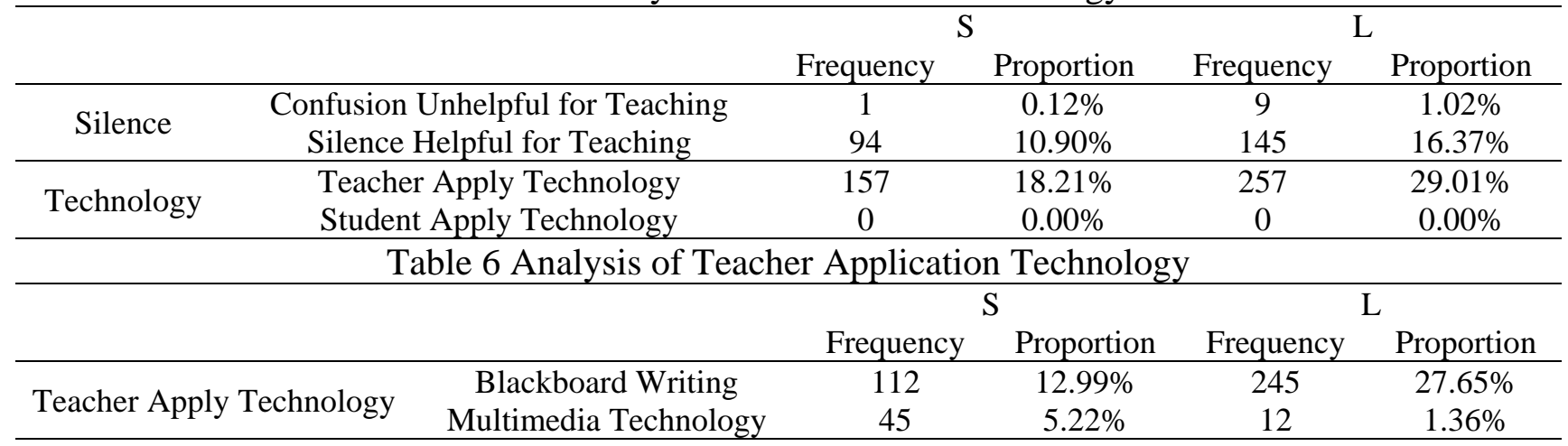


It can be seen most of the silence is effective. Only once invalid silence of S appeared in the $26^{\prime} 57^{\prime \prime}$. At that time, $\mathrm{S}$ reminded a student who had a nap and then there was an invalid silence. While $\mathrm{L}$ had nine times invalid silence, mostly occurred after lecturing or writing. The reason is unfamiliar with the textbook.

In the latter part of the class, two teachers both used the multimedia technology to review the contents. The most remarkable things is that the frequency of L using blackboard writing up to 245 times, accounting for $27.65 \%$. At the end of the class the blackboard writing seems so complex. Students reflected that they have transcribed the complex writing continually. In teacher L's opinion; the knowledge of Chemical Equilibrium Constant is highly theoretical. So L used the blackboard showing the context of the knowledge. Compared with teacher S, another important reason is that $\mathrm{L}$ wrote a lot of inefficient blackboard writing. For example, when defining the Chemical Equilibrium Constant, S only presented the keywords. However, teacher L merely "moved" the definition on the blackboard from the textbook.

\subsection{Analysis That Refer to Classroom Language}

The detailed statistics of Table 7 and table 8 are obtained by iFIAS.

Table 7 The Analysis of Interaction Behavior

\begin{tabular}{|c|c|c|c|c|c|}
\hline Category & Category & \multicolumn{2}{|c|}{$\mathrm{S}$} & \multicolumn{2}{|c|}{$\mathrm{L}$} \\
\hline 1 & Accepts Feeling & $0.00 \%$ & 0 & $0.11 \%$ & 1 \\
\hline 2 & Praises or Encourages & $0.00 \%$ & 0 & $0.90 \%$ & 8 \\
\hline 3 & Accepts or Uses Ideas of Student & $5.45 \%$ & 47 & $3.38 \%$ & 30 \\
\hline & 4.1 Asks Opening Problems & $0.12 \%$ & 1 & $1.35 \%$ & 12 \\
\hline 4 & 4.2 Asks Closed Problems & $12.75 \%$ & 110 & $3.83 \%$ & 34 \\
\hline 5 & Lecturing & $41.71 \%$ & 360 & $36.41 \%$ & 323 \\
\hline 6 & Giving Directions & $0.46 \%$ & 4 & $1.69 \%$ & 15 \\
\hline 7 & Criticizing or Justifying Authority & $0.23 \%$ & 2 & $0.00 \%$ & 0 \\
\hline 8 & Student Response Passively & $9.15 \%$ & 79 & $4.62 \%$ & 41 \\
\hline & 9.1 Student Response Initiatively & $0.35 \%$ & 3 & $0.11 \%$ & 1 \\
\hline 9 & 9.2 Student Question Initiatively & $0.12 \%$ & 1 & $0.00 \%$ & 0 \\
\hline 10 & Discuss with partner & $0.35 \%$ & 3 & $1.24 \%$ & 11 \\
\hline 11 & Confusion Unhelpful for Teaching & $0.12 \%$ & 1 & $1.01 \%$ & 9 \\
\hline 12 & Silence Helpful for Teaching & $10.89 \%$ & 94 & $16.35 \%$ & 145 \\
\hline 13 & Teacher Apply Technology & $18.31 \%$ & 158 & $28.97 \%$ & 257 \\
\hline 14 & student Apply Technology & $0.00 \%$ & 0 & $0.00 \%$ & 0 \\
\hline
\end{tabular}

Table 8 The Analysis of Interaction Behavior

\begin{tabular}{|c|c|c|c|}
\hline Item & Calculation formula & $\mathrm{S}$ & $\mathrm{L}$ \\
\hline $\begin{array}{c}\text { The Proportion of Indirect Influence to Direct } \\
\text { Influence }\end{array}$ & $\sum_{i=1}^{4}$ tally(i)/ $\sum_{i=5}^{7}$ tally $(i)$ & $43.17 \%$ & $25.15 \%$ \\
\hline $\begin{array}{c}\text { The Proportion of Positive Integration to Negative } \\
\text { Integration }\end{array}$ & $\sum_{i=1}^{3}$ tally(i)/ $\sum_{i=0}^{7}$ tally $y(i)$ & $783.33 \%$ & $260.00 \%$ \\
\hline The Proportion of Asks Question to Teacher Talk & $\sum$ tally $(4) / \sum_{i=1}^{7}$ tally $(i)$ & $21.18 \%$ & $10.87 \%$ \\
\hline $\begin{array}{c}\text { The Proportion of Student Talk-Initiation to } \\
\text { Student Talk }\end{array}$ & $\sum$ tally(9)/ $\sum_{i=8}^{10} \operatorname{tally}(i)$ & $4.65 \%$ & $1.89 \%$ \\
\hline $\begin{array}{c}\text { The Proportion of Asking Opening Problems to } \\
\text { Asking Problems }\end{array}$ & $\sum$ tally $(4.1) / \sum$ tally $(4)$ & $0.90 \%$ & $26.09 \%$ \\
\hline $\begin{array}{c}\text { The Proportion of Student Question Initiatively to } \\
\text { Student Talk-Initiation }\end{array}$ & $\sum$ tally $(9.2) / \sum$ tally $(9)$ & $25.00 \%$ & $0.00 \%$ \\
\hline
\end{tabular}

$\mathrm{S}$ and $\mathrm{L}$ had more direct impact on students than indirect impact, both of them inclined to control the classroom directly. However teacher L's indirect effect only accounted for $25.15 \%$. Classroom observation also found that $\mathrm{L}$ is less concerned about the students.

Positive reinforcement of two teachers is much higher than the negative one. In teacher S' class, the majority of students answer the questions. On the contrary, after asking questions, L needed to make specific instructions to students. Relatively, S puts forward some question following the ZPD of the students. At the same time, $\mathrm{S}$ can condense the attention of students and mobilize the enthusiasm of the students. 
In addition, in this section, Chemical Equilibrium Constant, the current chemistry textbooks have presented the experimental data. Teacher $S$ used nearly 8 minutes $\left(05^{\prime} 0^{\prime \prime}-13^{\prime} 0^{\prime \prime}\right)$ to analyze the data. $S$ not only guided students to discovered that regardless of the initial concentration changes the expression $C^{2}(\mathrm{HI}) /\left[C\left(\mathrm{H}_{2}\right) \cdot C\left(\mathrm{I}_{2}\right)\right]$ are a certain value but also used the data to explain the student misconceptions. Instead, teacher L only spent 2 minutes $\left(03^{\prime} 0^{\prime \prime}-05^{\prime} 23^{\prime \prime}\right)$. This fact shows that $\mathrm{L}$ failed to use the internal resources of the chemistry textbook. While proficient teacher $\mathrm{L}$ not only discovered students' misunderstandings timely but also reasonably explained the problems. It is a reasonable teaching method that teacher guide students to observe, discover, summarize and conclude.

\section{Conclusion and Suggestion}

Through classroom observation and iFIAS analysis, novice teachers ought to improve themselves in the following aspects: (1) on creating classroom atmosphere, harmonious classroom atmosphere have a promotion to students' initiatively speaking and actively learning [7]. In order to create a harmonious atmosphere, novice teachers should master the structure of curriculum knowledge and pay more attention to the students. (2) In the ratio of teachers and students' language, both proficient teachers and novice teachers are under improvement. Outstanding teachers should focus on the students rather than the subject, manage and monitor students on the premise of love and respect [8]. Compared to the proficient teachers, novice teachers' not well at controlling the speech speed of classroom teaching. Actually timely pause helps to give students more time to think and achieves the good teaching effect.(3) On the teaching technology application, unnecessary blackboard writing can take up the students' reading time, affect the students' thinking and have negative effect on teaching [9]. Novice teachers should enhance blackboard writing design. The reasonable use of education technology can ensure the teaching effectiveness and efficiency. (4) On the use of textbooks. During the practice, proficient teachers have accumulated a wealth of experience and had the capacity to enrich the teaching content. They have their own unique views on the textbooks [10]. Therefore, it is necessary for novice teachers to study and use the teaching material neatly during their professional development.

\section{Acknowledgments}

This thesis is a key project of education reform in Higher Education in Shaanxi Province in 2015: based on the concept of cooperative education for "the construction of outstanding teacher training system", it is the stage achievement [2015] 21of higher education in Shaanxi Province.

\section{References}

[1] The ministry of education on the opinions of the outstanding teacher training plan [EB/OL]. http://www.moe.gov.cn/srcsite/A10/s7011/201408/t20140819_174307.html, 2014-08-18/2016-9-25.

[2] Fanzhe Kong. Preparing lessons in order: preparing lessons and new skills [M]. Changchun: Northeast Normal University Press, 2008, p.110.

[3] Yi Shen, Yunkuo Cui. Classroom observation: toward a professional evaluation class [M]. Shanghai: East China Normal University Press, 2008, p. 74.

[4] Rong Lian. Comparison of the psychological characteristics of novice, proficient and expert teachers [J]. Acta Psychologica Sinica. Vol. 36 (2004) No. 01, p. 44-52.

[5] N. A. Flanders. Analyzing Teaching Behavior [M]. New York: MA. Addison-Wesley Publishing Company, 1970. 
[6] Haiguang Fang, Chenzhu Gao, Jia Chen. Improved Flanders Interaction Analysis System and its application [J]. China Educational Technology. (2012) No. 10, p. 109-113.

[7] Chengyin Yang, Caifeng Feng, Jingjing Liu. Ideal classroom: the chemistry teachers' professional development from the reality to the ideal [J]. Education in Chemistry. (2015) No. 05, p. 18-22.

[8] Xiao Yang, Dekun Cui. The current situation and trend of the study of "excellent teachers" [J]. Journal of Teaching and Management. (2016) No. 09, p. 9-12.

[9] Sen Li, Shangrong Du. A study of classroom teaching management strategies -- Based on the case analysis [M]. Fuzhou: Fujian Education Press, 2013, p. 167.

[10]Guoliang Liu. The development of basic education teachers: the pursuit and Transcendence [M]. Hangzhou: Zhejiang University Press, 2014, p. 92. 